\title{
Screening brief
}

\section{Neonatal screening for cystic fibrosis}

Birth prevalence

- Approximately 1 in 2500 live births in populations of Western European origin; similar prevalence in Jewish populations.

General characteristics

- Inheritance is autosomal recessive.

- One in 25 people is a carrier.

- More than 850 cystic fibrosis (CF) gene mutations have been identified; four mutations account for about $85 \%$ of the total. ${ }^{1}$

- Incidence of different mutations varies according to ethnic composition of populations.

Natural history

- $10-15 \%$ of newborns with CF require abdominal surgery to remove intestinal meconium plugs.

- Abnormal mucus secretion leads to chronic progressive lung damage.

- Intense respiratory management by inhalants, antibiotics, and physical therapy improves survival.

- Intestinal absorption of dietary protein and fat is impaired by a lack of pancreatic enzymes.

- Lung damage from cystic fibrosis leads to it being the main indication for heart-lung transplants.

- Expectation of life about 30 years. $^{23}$

Screening procedure

- In newborns, radioimmunoassay for immunoreactive trypsin (IRT) on dried blood spots. ${ }^{4}$ False positive rate is dependent on the cut-off level of IRT but this is typically set to give a false positive rate of between $0.3 \%$ and $0.6 \%{ }^{5}$

- Two or three stage procedures with or without subsequent DNA analyses have been developed to reduce false positive diagnoses. ${ }^{4}$ IRT followed by IRT again if positive yields a $90 \%$ detection rate for a $0.3 \%$ false positive rate. IRT and DNA if IRT test is positive yields a $97 \%$ detection rate for a $0.7 \%$ false positive rate. ${ }^{6}$

- Detection rate between $85 \%$ and $90 \%$ conventionally calculated excluding infants with meconium ileus, but may be overestimated due to underascertainment of milder cases of $\mathrm{CF}^{4}{ }^{4}$

Subsequent tests

- Diagnosis is based on the Sweat test: a sweat chloride $>60 \mathrm{mEq} / \mathrm{L}$ in association with a clinical sign of cystic fibrosis is judged diagnostic. ${ }^{5}$ DNA analysis is corroborative, but not essential.

- Even with a 30 mutation panel DNA will only detect at most $85-90 \%$ of carriers, and therefore less cases. ${ }^{5}$

Intervention

- Early treatment is intended to improve nutrition, and to prevent or minimise lung damage.

- Regular assessment for early intervention as problems arise.

- Prenatal diagnosis in subsequent pregnancies.

Current evidence

- The Cochrane review ${ }^{7}$ reports only two randomised controlled trials, one in the $\mathrm{UK}^{8}$ and one in the USA ${ }^{9}{ }^{10}$ involving 1124483 neonates and a total of 210 patients with cystic fibrosis.

- The UK trial, comparing 102 cystic fibrosis children, 58 detected through screening and 44 diagnosed clinically (including nine with false negative screening results) showed no clinical differences between groups up to age 4 .

- The US trial was based on a comparison of 74 cystic fibrosis children who had been screened (including five false negatives) and 40 cystic fibrosis children diagnosed clinically. In 1997 the investigators reported a significant reduction in the incidence of reduced height and weight, ${ }^{9}$ but due to methodological design leading to possible bias in the first four years, ${ }^{11}$ these results were difficult to interpret. Since then, a longer follow up indicates that screening can avoid small stature and low body weight. ${ }^{10}$ However, the impact of screening on lung disease and overall prognosis remains unknown.

- A UK Health Technology Assessment report published in 1999 is a comprehensive data source on neonatal cystic fibrosis screening. ${ }^{6}$

Overall assessment

- Insufficient evidence that neonatal screening for cystic fibrosis is worthwhile.

- The position needs review in the light of further data from randomised trials of screening with lung disease and survival and quality of life included as important endpoints.

1 Cystic Fibrosis Mutation Data Base (www.genet.sickkids.on.ca/cftr/)

2 Elborn JS, Shale DJ, Britton JR. Cystic fibrosis: current survival and population estimates to the year 2000. Thorax 1991;46:881-5.

3 Cystic Fibrosis Foundation. Patient Registry 1999 Annual Report. Bethesda: Cystic Fibrosis Foundation, 2000.

4 Pollit RG. Screening for cystic fibrosis. Semin Neonatol 1998;3:9-15.

5 Brock DJH. Cystic Fibrosis. In: Wald NJ, Leck I, eds. Antenatal and Neonatal Screening, 2nd edn. Oxford: Oxford University Press, 2000.

6 Murray J, Cuckle H, Taylor G, et al. Screening for cystic fibrosis. Health Technol Assess 1999;3:8

7 Merelle ME, Lees CM, Nagelkerke NF, et al. Newborn screening for cystic fibrosis (Cochrane Review). In The Cochrane Library 2000;(4). Oxford: Update Software.

8 Chatfield S, Owen G, Ryley HC, et al. Neonatal screening for cystic fibrosis in Wales and the West Midlands: clinical assessment after five years of screening. Arch

Dis Child 1991;66:29-33.
9 Farrell PM, Kosorok MR, Laxova A, et al. Nutritional benefits of neonatal screening for cystic fibrosis. N Engl f Med 1997;337:963-9.

10 Farrell PM, Kosorok MR, Rock MJ, et al. Early diagnosis of cystic fibrosis through neonatal screening prevents severe malnutrition and improves long-term growth. Pediatrics 2001;107:1-13.

11 Wald NJ, Morris JK. Neonatal screening for cystic fibrosis. BMF 1998;216:404-5.

Reproduced with permission from the fournal of Medical Screening 2001;8:51. 